\title{
Robotics and Automation Activities at the Savannah River Site - A Site Report for SUBWOG 39F
}

by

G. D. Teese

Westinghouse Savannah River Company

Savannah River Site

Aiken, South Carolina 29808

A document prepared for SUBWORKING GROUP 39F - AUTOMATION AND ROBOTICS at Aldermaston from 10/16/95 - 10/20/95.

DOE Contract No. DE-AC09-89SR18035

This paper was prepared in connection with work done under the above contract number with the U. S. Department of Energy. By acceptance of this paper, the publisher and/or recipient acknowledges the U.S. Government's right to retain a nonexclusive, royalty-free license in and to any copyright covering this paper, along with the right to reproduce and to authorize others to reproduce all or part of the copyrighted paper.

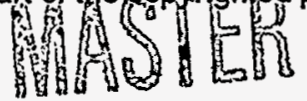




\section{DXSCLAIMER}

This report was prepared as an account of work sponsored by an agency of the United States Government: Neither the United States Government nor any agency thereof, nor any of their employees, makes any warranty, express or implied, or assumes any legal liability or -responsibility for the accuracy, completeness, or usefulness of any information, apparatus, product, or process disclosed, or represents that its use would not infringe privately owned rights. Reference herein to any specific commercial product, process, or service by trade name, trademark, manufacturer, or otherwise does not necessarily constitute or imply its endorsement, recommendation, or favoring by the United States Government or any agency thereof. The views and opinions of authors expressed herein do not necessarily state or reflect those of the United States Government or any agency thereof.

This report has been reproduced directly from the best available copy.

Available to DOE and DOE contractors from the Office of Scientific and Technical Information, P.O. Box 62, Oak Ridge, TN 37831; prices available from (615) 57.6-8401.

Available to the public from the National Technical-Information Service, U.S. Department of Commerce, 5285 Port Royal Road, Springfield, VA 22161. 


\section{DISCLAIMER}

Portions of this document may be illegible in electronic image products. Images are produced from the best available original document. 


\title{
ROBOTICS AND AUTOMATION ACTIVITIES AT THE SAVANNAH RIVER SITE -
}

\section{A SITE REPORT FOR SUBWOG 39F}

\author{
Gregory D. Teese \\ Westinghouse Savannah River Company \\ Savannah River Technology Center \\ Robotics and Remote Systems Group \\ Building 773-A \\ Aiken, SC 29808 \\ 803-725-2051 \\ 803-725-7369 (Fax) \\ gregory.teese@srs.gov
}

\begin{abstract}
The Savannah River Site (SRS) has successfully used robots, teleoperators, and remote video to reduce exposure to ionizing radiation, improve worker safety, and improve the quality of operations. Previous reports have described the use of mobile teleoperators in coping with a high level liquid waste spill, the removal of highly contaminated equipment, and the inspection of nuclear reactor vessels. This report will cover recent applications at Savannah River, as well as systems which SRS has delivered to other DOE site customers.
\end{abstract}

\section{INTRODUCTION}

The Savannah River Site (SRS) is an isotope production facility operated by the Westinghouse Savannah River Company (WSRC) for the United States Department of Energy (DOE). It was established in the early 1950s to produce nuclear materials primarily for national defense. The $300 \mathrm{mi}^{2}\left(777 \mathrm{~km}^{2}\right)$ complex, located in South Carolina, is composed of many separate plant operations, including fuel and target fabrications, nuclear reactors, chemical separations, and numerous waste handling facilities.

The Savannah River Technology Center (SRTC) is the applied research and development arm of the Savannah River Site. SRTC was formerly known as the Savannah River Laboratory. Within SRTC, the Equipment Engineering Section provides specialized equipment systems for use with radioactive materials. The Robotics and Remote Systems group is one of the groups which comprise the Equipment Engineering Section.

The Robotics and Remote Systems group was established in 1982 to bring the emerging technology of robotics to the site. Since its inception, the group has been concerned with the application of robots, teleoperators, and associated auxiliary equipment, such as remote video systems. Successful applications in 
previous years include the installation of a robot to bag-out californium waste, the use of mobile teleoperators to perform a variety of tasks in high contamination or high radiation environments, the use of mobile robots to perform routine radiation surveys, and the development of numerous innovative video systems.

Industrial robots have found fewer applications in recent years as the number of repetitive production operations at SRS have decreased. However, mobile teleoperators, mobile robots and specialized video systems continue to play a major role in the continuing effort to reduce worker exposure, increase worker safety, and improve operations. Recent applications of these technologies are detailed below.

\section{MOBILE TELEOPERATORS}

SRTC has a fleet of mobile teleoperators to respond to a variety of potential situations. The majority of the fleet is comprised of vehicles with origins in the bomb-disposal market. A recent addition to this fleet is "Little MoRT", a Mobile Radio-controlled Teleoperator. Little MoRT combines the high strength and dexterity of a Schilling Titan 7F manipulator with the agility of a Cushman Stockchaser vehicle. The resulting combination can operate indoors or out, fit through a typical doorway, and lift 250 pounds $(113 \mathrm{~kg})$. Control of the vehicle is accomplished through a "universal controller" which operates most of the vehicles in the fleet. Manipulator control is accomplished over a separate radio link, using off-the-shelf equipment from Schilling Development.

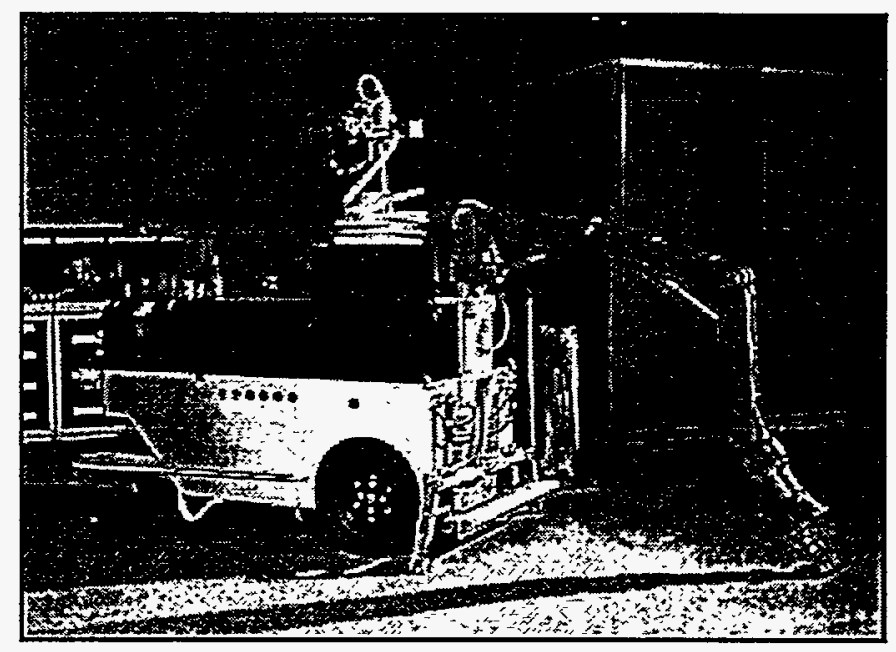

Figure 1 - Little MoRT, a Mobile Teleoperator

\section{Pipe Crawlers and Pigs}

A specialized subset of mobile teleoperators are those machines designed to work inside piping systems. Pipe crawlers with wheels or treads may be used in horizontal piping systems, such as sewers, drains, etc. Inch-worm motion devices use expansion and contraction of legs and body segments to move step- 
wise along pipes. By firmly gripping the inner diameter, inch-worm motion devices are capable of negotiating vertical piping segments. Piston based systems, commonly referred to as "pigs" are propelled by differential pressure. Since "pigs" do not require a power tether, they are frequently used in piping systems with multiple bends and elbows. Advances were made in all three areas recently.

A treaded crawler based upon components from Inuktun was used to transport radiation monitoring equipment through an abandoned drain line to determine if remediation efforts would be required. Conventional technology to address the problem would have involved drilling a very large number (over 300 ) monitoring wells to determine if radionuclides had entered the environment surrounding the pipeline. Use of the crawler to perform a radiological survey inside the pipe reduced the number of wells significantly, and minimized the remediation activity. Special considerations in this application included deployment tooling, and calibration of the radiation detectors with the long cables required.

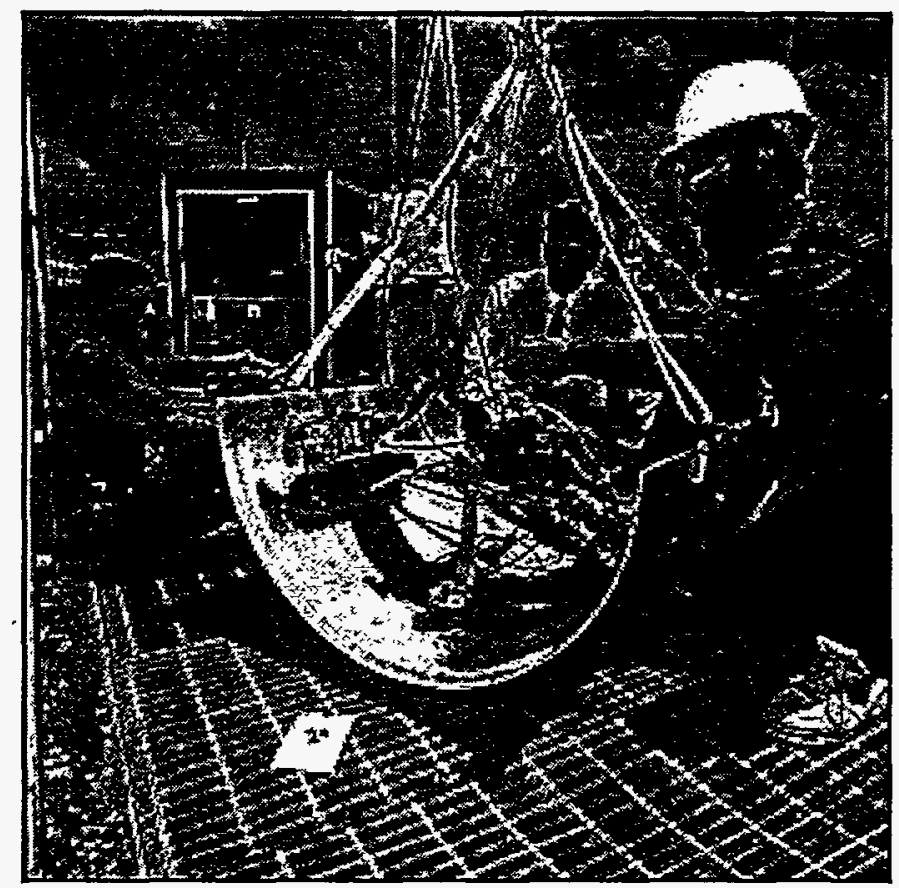

Figure 2 - Inuktun Crawler Modified for Drain Line Inspection

Inch-worm motion devices have been previously demonstrated for nondestructive examination of reactor piping systems. The changing pipe diameters found at Savannah River reactors necessitated development of a crawler capable of changing diameters in transit. This technology was recently applied to in-situ modification of ventilation system piping. The $36^{\prime \prime}(.91 \mathrm{~m})$ ventilation pipe carried HEPA-filtered exhaust air from a plutonium handling facility to a fan house prior to exhausting it to the atmosphere. The pipe runs coaxially with a ventilation tunnel during much of its length. The ventilation tunnel carries exhaust air from a radiochemical processing plant to a sand filter system. It was desired to redirect 
the air from the ventilation pipe to the ventilation tunnel, so that it, too, would exhaust through the sand filter. Conventional approaches to this problem would involve a total shutdown of facility ventilation, excavation to uncover the tunnel, breaching the contamination barrier of the tunnel wall, and then using personnel in protective clothing to modify the piping system. The innovative solution utilized a custom built, inch-worm motion crawler equipped with a plasma-arc cutting torch. Only the ventilation from the plutonium facility was shutdown, and the crawler was introduced to the system at the fan house. It traversed nearly 300 feet $(91 \mathrm{~m})$ to an elbow in the pipe inside the ventilation tunnel. The plasma arc torch was used to make two circumferential cuts; one on each side of the elbow. The elbow was abandoned on the floor of the tunnel, and the crawler was retrieved for disposal.

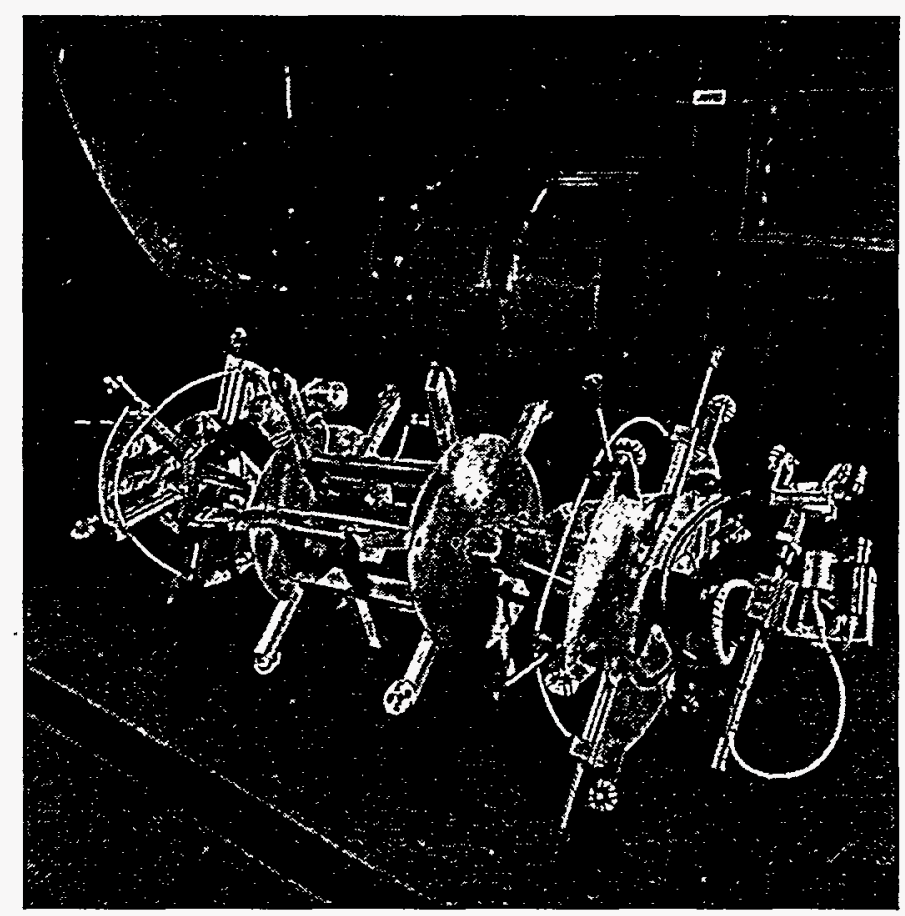

Figure 3 - Inch Worm Motion Crawler Equipped with Plasma Arc Torch

A piston based system has recently been developed to inspect cooling coils used in SRS waste tanks. The coils are made from $2 "(5 \mathrm{~cm})$ diameter pipe and have numerous bends as they loop within the tank. Each tank has 23 systems, each with independent valving to provide controlled heat removal, and redundant capability. The small diameter and numerous bends eliminated tethered crawlers, while the sludge and salt in the tank prohibited access to the outside diameter of the pipe. A piston based system, similar to the "pigs" used for gas and oil piping, has been developed. This system, known as the "Pipe Rabbit," is propelled by controlling the differential pressure across the device, and can actually be positioned quite repeatably when coupled to a positive displacement pump under computer control. Water is used as the working fluid, as that is the normal fluid used in the cooling coils. Position feedback is obtained from the number of revolutions of the positive displacement pump, while pressure 
transients associated with welds and elbows are used to confirm the position. Data is transmitted over a fine twisted pair wire which is deployed from the rear of the device. Battery modules are molded into the body, to supply power to data collection instruments. Current efforts are centered on development techniques for material condition assessment, such as eddy current or ultrasonics.

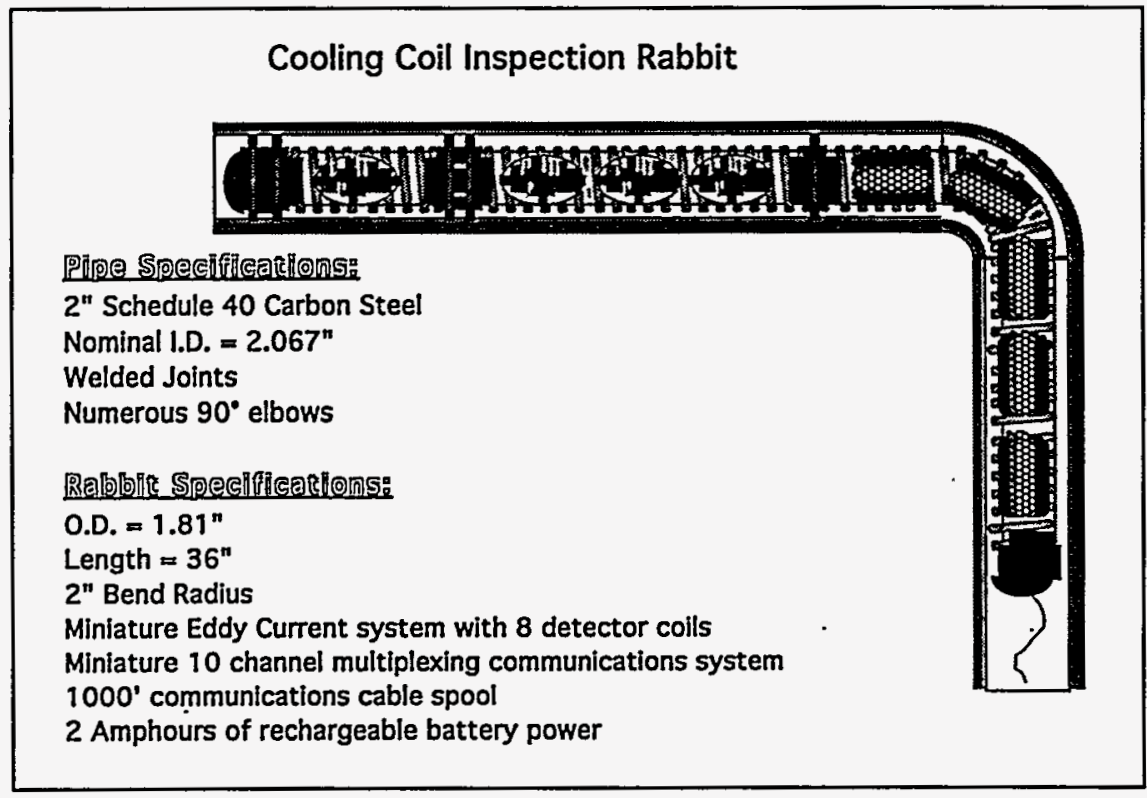

Figure 4 - Artist's Conception of Piston Based System Known as the Pipe Rabbit

\section{MOBILE ROBOTS}

Mobile robots are an extension of wireless automated guided vehicles (AGVs). Conventional AGVs are typically constrained to a path, defined by buried signal wires, chemical stripes, or reflective tape. Wireless AGVs use other navigation cues, such as triangulation off of landmarks. Mobile robots rely primarily on dead reckoning or inertial navigation, and use landmarks or other environmental cues to reduce accumulated errors. SRTC began investigating mobile robots with ALVIN, the Autonomous Laboratory Vehicle with Intelligent Navigation in 1986. ALVIN used a Cybermotion K2A as the robotic base, and carried research application packages developed in-house. The first practical use of a mobile robot was the Semi-Intelligent Mobile Observing Navigator, SIMON, which combined the mobile robot experience of ALVIN with gas flow proportional radiation detection technology from Eberline. SRTC developed an on-board host computer system to alter the robot's behavior in response to sensed radiation levels. SIMON has been used to find previously undetected incidents of fixed contamination.

The Oak Ridge National Laboratory (ORNL) requested SRTC to deliver a system similar to SIMON in 1995. The new system, MACS (Mobile Automated Characterization System) is conceptually similar to SIMON, but features a laser 
based system to improve navigation in open areas, more powerful on-board computers, and scintillation type radiation detectors. The system has been delivered, and is scheduled to be used to survey 300 acres of floorspace in uranium enrichment facilities at Oak Ridge.

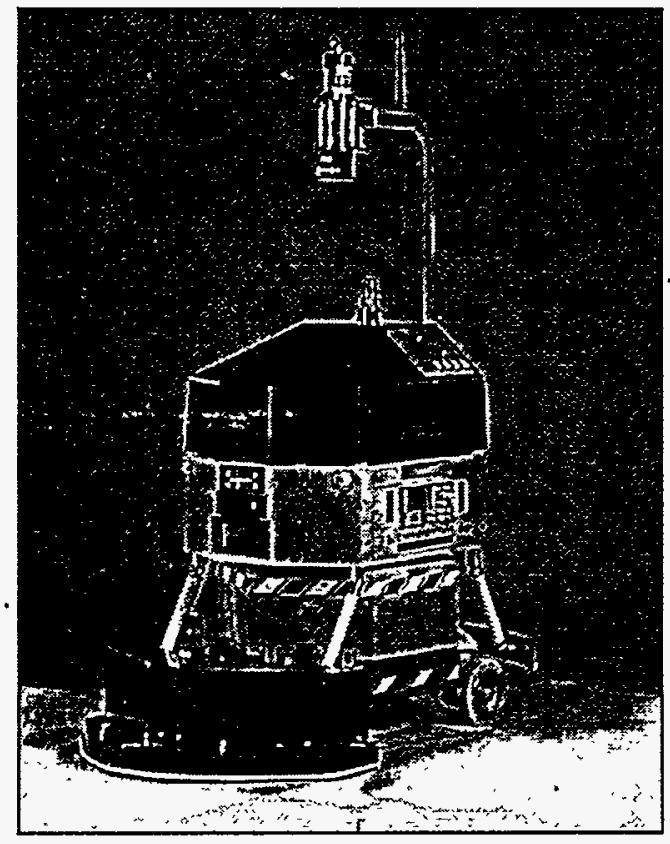

Figure 5 - MACS - A Mobile Robot for Floor Contamination Detection

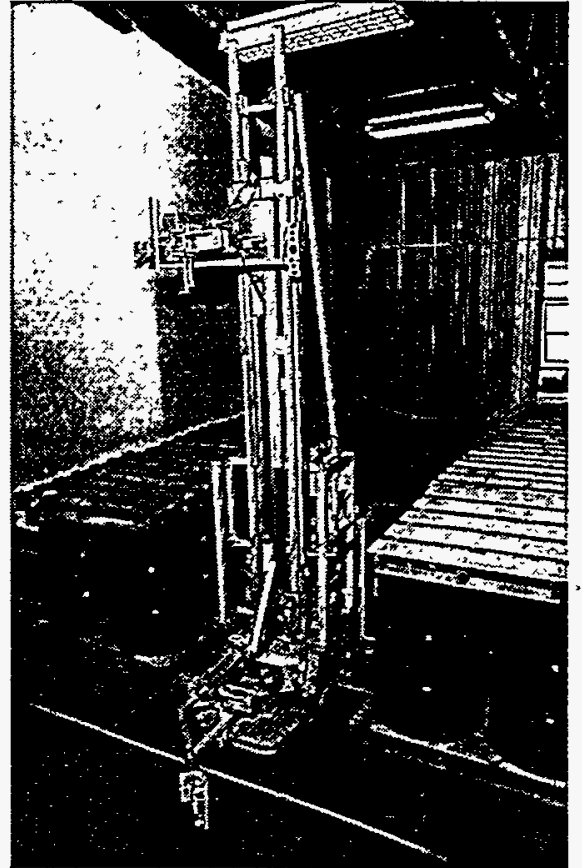

Figure 6 - SWAMI-II, Rear View - A Mobile Robot for Drum Inspection

Another mobile robot system was also delivered in 1995. The second generation of the Stored Waste Autonomous Mobile Inspector (SWAMI-II) is now undergoing start-up testing at the Fernald site in Ohio, a former uranium processing facility. SWAMI-II will perform routine inspections of drummed radioactive waste stored in warehouses awaiting final disposal. Using a robot for this regulatory mandated inspection will improve the repeatability of data collection, improve documentation, and reduce chronic exposure to low level radiation. SWAMI and SWAMI-II are both based on Transitions Research Corporation (TRC) Helpmate ${ }^{\circledR}$ vehicle. In addition to barcode scanners and video cameras, SWAMI-II also features a laser based measuring system to detect bulges, blisters and dents in the drums.

A special mobile robot for use on steel tank walls was also developed recently. The "wall crawler" uses magnetic wheels to attach to the vertical tank walls, and has independent left and right drive motors to accomplish skid steering. Navigation is confined to dead reckoning currently. Application packages attached to the wall crawlers include ultrasonic testing (UT) packages, surface preparation tools, and observation camera systems. One family of wall crawlers has been delivered to the West Valley Nuclear Services site, a former reprocessing facility, to assess material condition of the steel tank walls in their liquid high level waste tanks. A second family is in use at SRS, and has collected 
material condition data on a number of active high level waste tanks. Twelve wall thickness maps on three different tanks have been generated at SRS, and a continuing program to inspect the remaining tanks has been established.

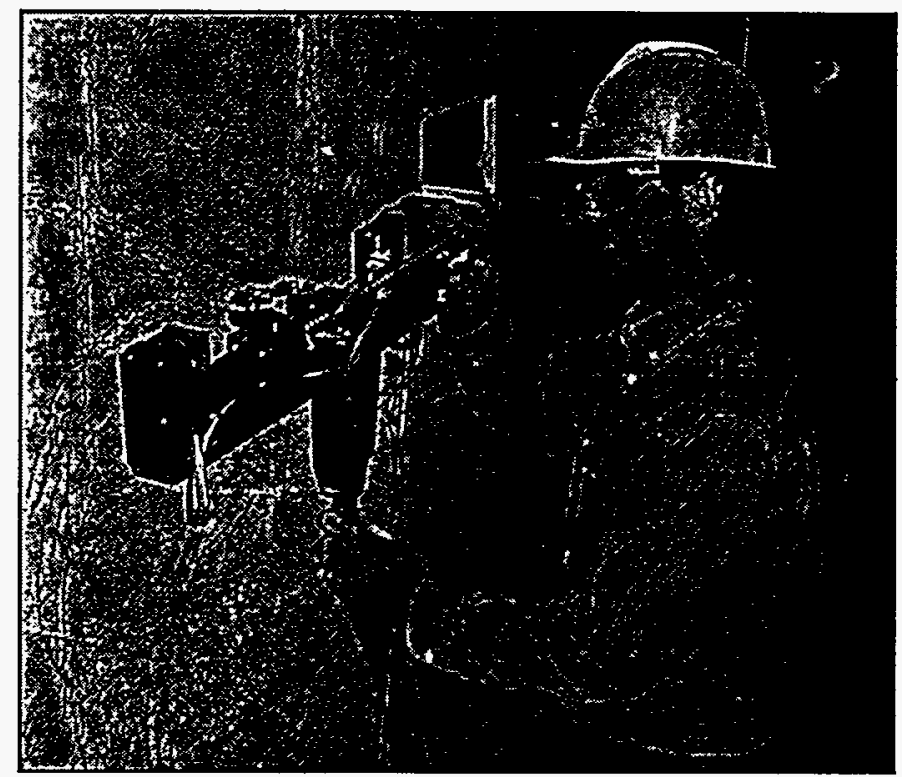

Figure 7 - Magnetic Wheeled Wall Crawler

\section{SPECIALIZED VIDEO SYSTEMS}

SRTC continues to supply the DOE complex with innovative video systems. Five families of equipment have been delivered recently, each of which may have broad applications at nuclear facilities. Three of these are video end effectors designed to be used with the Light Duty Utility Arm (LDUA) being developed by DOE for use in remediating underground storage tanks. The other two are stand alone systems, and may be used in a variety of situations.

The video end effectors are both specialized systems designed to be used with the LDUA. The first is the Optical Alignment System (OAS) and is intended to be the end effector used with the LDUA when it is first inserted into an underground storage tank. The entry risers to many of the tanks have not been surveyed for determination of out-of-round, off-vertical, or other abnormal conditions. If such a condition were to exist, then the arm of the LDUA might become stuck when it is inserted into the riser. The OAS combines video viewing of the riser during entry with non-contact gauging of the riser during the entry process. Laser lines are also projected along the length of the riser during insertion to aid operators in centering the arm during insertion, and determining abnormal conditions.

After proper positioning of the LDUA is accomplished, removal and reinsertion can be accomplished with confidence. A second video end effector has been designed to assist in remediation efforts by providing video feedback of operations. Close up stereo and wide angle view cameras are provided to 
evaluate suspect anomalies and tank condition. This system also has the unique ability to increase magnification by a known increment, allowing operators to deduce the true size of objects.

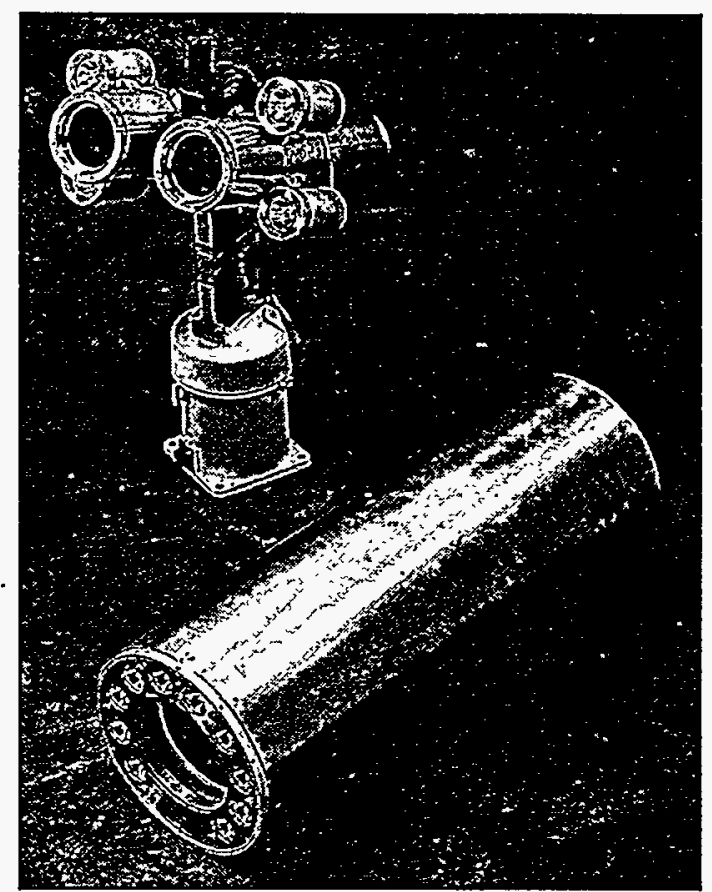

Figure 8 - Two of the Video End Effectors for the Light Duty Utility Arm

The third end effector provides stereo film documentation of remote tank

interiors. The film capability is being retained because its resolution is on the order of ten times better than that which is available with video. Real-time scene viewing and adjustment are provided with internal video cameras.

One of the families of stand alone systems may also be used to support remediation operations, as well as other video viewing needs in tanks, wells, or other underground structures. These systems consist of a tubular camera and light assemblies deployed from a cable reel, and are capable of being inserted into 4 inch $(10 \mathrm{~cm})$ diameter risers or casings. The systems are sealed for use in explosive atmospheres, and features a gas purge system to ensure positive pressure in the housing and cable enclosure. Pan motion is accomplished by rotation of the camera housing with respect to the support cable enclosure, while tilt motion is accomplished by altering the angle of a mirror at the end of the camera. The mirror is constructed of metal, using first-surface technology to eliminate the use of glass, which may shatter or brown during use. Radiation hardened mono-optic and color stereo versions have been delivered, and are undergoing qualification testing. Similar systems have also been deployed in the annular space of double shelled tanks.

The final video system family presented is intended to be used with overhead cranes. The "Camera-In-a Drum" or CID, is a compact camera mounted to a pan 
and tilt unit, along with integral lighting. Control of the camera functions and auxiliary functions are multiplexed on the video signal to minimize control wiring, and simplify field deployment. This technique is also known as "control on the video" and can be accomplished over either a single coaxial or fiber optic cable, reducing the cable burden. The system is packaged in a stainless steel housing, or drum, to protect it from inadvertent damage during operation. CID systems have been used to observe operating equipment during nuclear fuel reprocessing in facilities which did not provide this capability.

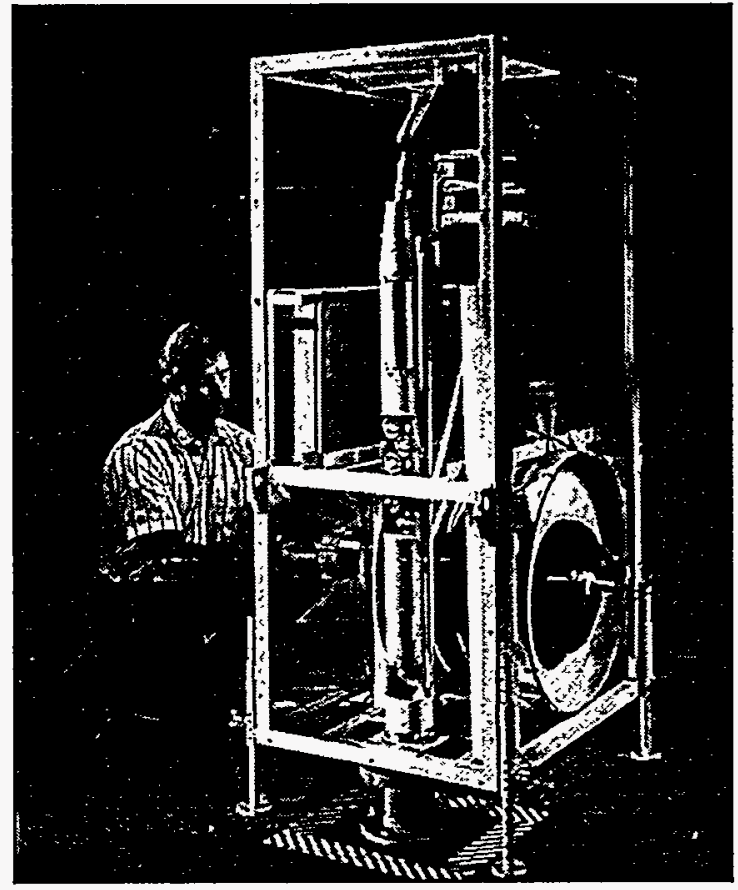

Figure 9 - A Stand Alone Video Inspection System for Tank Interiors

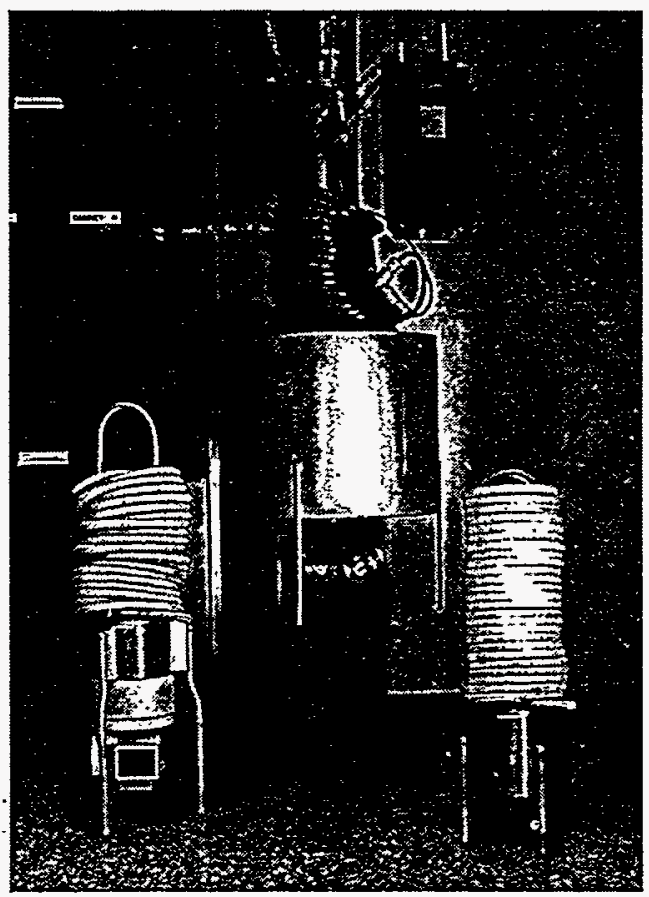

Figure 10 - Three Different CID Systems

\section{SUMMARY}

The use of mobile teleoperators, mobile robots, and specialized video systems have contributed to the reduction of exposure to ionizing radiation, improved worker safety, and increased the quality of operations, both at the Savannah River Site, and at the sites of our customers.

\section{ACKNOWLEDGMENT}

The information contained in this report was developed during the course of work performed under contract number DE-AC09-89SR18035 with the U.S. Department of Energy. 